\title{
Medicine and Flying
}

\section{The fun and fear of flying}

\author{
HUGH F THOMAS
}

The first time I flew solo I was nervous. As a 17 year old Air Training Corps cadet my preparation had been twenty two winch launches with an instructor in the Slingsby T 31 open glider: a total flying time of one hour. I was then briefed for three solo circuits. My visible shaking was assumed to be due to the cold November afternoon, and I was hastily lent a warm aircrew jacket before being sent alone into the air. On the first circuit I was too low on the final approach and was relieved to just clear the perimeter fence and reach the landing strip. The instructor berated me for this potentially disastrous error of judgment and then sent me off again for two thankfully uneventful circuits.

Two years later at an airfield near Southport I taxied out for my first solo flight in a powered aeroplane, a de Havilland Chipmunk. Again I felt nervous, but wearing a flying suit, helmet, parachute, and "Mae West" life jacket I felt dressed for the occasion. Indeed, I felt a strange sense of comradeship with the wartime fighter pilots who had raced down the same runway thirty years earlier to defend Liverpool. But my task was infinitely less demanding and my only enemies gravity and the weather. The short flight was uneventful and the landing quite reasonable (the saying being that a good landing is one you walk away from).

Instead of pursuing a military career I chose to work in public health, first as a public health inspector and later as a research officer at an epidemiology unit. At the age of 29 I was fortunate enough to be accepted for medical school and with my wife and young son moved up to Leicester. The house we bought turned out to be situated only two miles from a small airfield, and light aircraft came over regularly. The flying bug, which had lain dormant for ten years, began to stir. After completing three years of medical studies, I could not resist a short trial flight at the local aeroclub. The Cessna 152 is a small, docile, high wing two seater. Surprisingly, I had not forgotten everything and, hooked once more, after four and a half hours dual flying I went solo again. The fairly intensive dual revision had included stalling, spinning, engine failures, and other unusual events that one trusts will never happen. My previous university air squadron flying hours counted towards the requirements for obtaining the private pilot's licence, considerably reducing the time and expense involved.

Although I cannot afford to go up very often, half an hour a month between two and five thousand feet is excellent treatment to clear the head. A fellow medical student recently accompanied me, and we enjoyed surveying the city and county from high up and in one glance seeing most of the hospitals at which we train.

Medical School, University of Leicester

HUGH F THOMAS, medical student

Correspondence to: 19 Baden Road, Leicester LE5 5PA.
As I have flown over Leicestershire and the surrounding counties I have noticed the many disused wartime airfields that litter the countryside. Forty years ago most were active flying bases and the sky was often a hostile place. The biographies of wartime aircrew

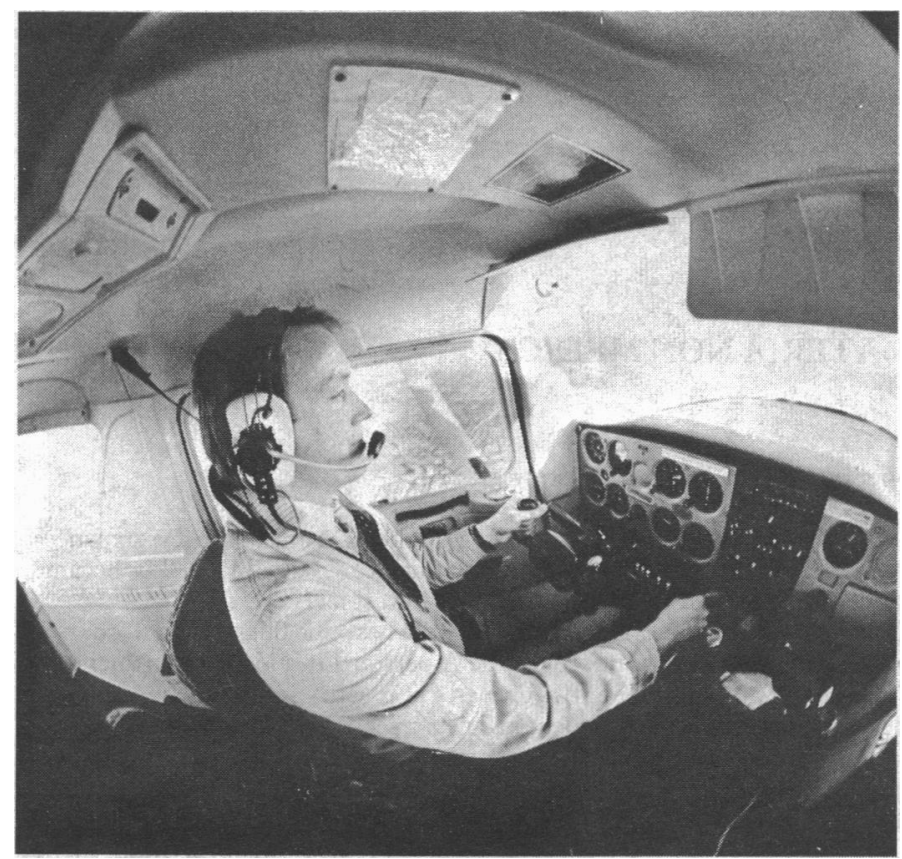

High above Leicester

[Photograph Stephen Thursfield

that I have read describe excitement and daring flying. Almost incidental to the main story there is mentioned the daily loss of comrades either missing or killed. The total loss of life was brought home to me on a recent visit to the Royal Air Force Museum at Hendon. The Bomber Command display records that some 47000 British and Commonwealth aircrew and 6000 United States airmen died in the bomber offensive against Germany. That represents some 10000 aeroplanes destroyed. At the worst time of that offensive the average survival of a bomber crew was eight missions before death, injury, or captivity intervened. The wartime chief of Bomber Command, Air Marshal Arthur "Bomber" Harris wrote: "They knew the odds were constantly against them to the point that they were playing never ending games of Russian roulette. I do not know why or how they went on as they did. I am lost in admiration for them.",

While I share Harris's admiration for the gallantry of such men, I can feel sympathy, perhaps empathy, for the other men, seldom 
talked about, who could not live with such stress. It was the study of psychological breakdown among bomber crews, observed Professor Geoffrey Rose in his obituary of Professor Donald Reid, that was the beginning of psychiatric epidemiology. The book by Revie is one of the few that I have seen that mentions this very real aspect of air warfare and gives some poignant personal accounts. He quotes one source suggesting that 2000 men were stripped of their rank and flying badges for what was at first known as "lacking in moral fibre" (LMF) and later as "forfeiting the CO's confidence." Such cases, when men refused to fly, malingered to avoid flying, or flew and deliberately did not fulfil their mission objectives in order to avoid danger, appear to have been dealt with at squadron level and kept from senior officers. Revie states that he raised this subject with $\mathrm{Sir}$ Arthur Harris after the war. He received the simple answer "LMF? What's that? I've certainly never heard of it!' I do not know what to make of that answer. Perhaps the problem was small. But if it did concern 2000 aircrew then it suggests that Harris was out of touch with the feelings of some of the men he commanded or he did not recognise the problem among the men whom he so greatly admired.

Today private flying is statistically safer than riding a motorbike, although when airborne one is aware that if anything goes wrong there is further to fall. But flying is exhilarating. One of the best short poems describing this is Dancing the Skies by John Magee (Skywriting. James Gilbert, 1978):
Oh I have slipped the surly bonds of earth And danced the skies on laughter silvered wings; Sunward I've climbed, and joined the tumbling mirth Of sun-split clouds-and done a hundred things You have not dreamed of-wheeled and soared and swung Hung in the sunlit silence. Hov'ring there I've chased the shouting wind along, and flung My eager craft through footless halls of air

Up, up the long, delirious, burning blue I've topped the wind-swept heights with easy grace

Where never lark, nor even eagle flewAnd while with silent, lifting mind I've trod

The high, untrespassed sanctity of space, Put out my hand and touched the face of God

Magee was an American serving with the Royal Canadian Air Force. He was only 19 in 1941 when his Spitfire rammed another aircraft in cloud and he was killed. The poem was found on the back of an envelope among his personal effects.

\section{Reference}

1 Revie A. The lost command. London: Corgi Books, 1972.

\title{
Have jet, will fly
}

\author{
D E BRADFORD
}

Being sick at the speed of sound can hardly be called projectile vomiting but, in the back seat of a Phantom F4, the effect could have been as dramatic. A quick struggle with the retaining clip on my oxygen mask and a rapid grab for the standard issue "bag, air sickness Nato stock No 8105-99-130-2180" and in a few seconds it was all over. This minor upset did little to spoil what was for me a most successful first flight in a fast jet and the climax of two years' discussion on my suitability to fly.

Eight years before that day when I journeyed forth at just over Mach 1 I had suffered a myocardial infarction and two years before had had a triple coronary artery bypass graft for increasing angina. A respectable time after surgery, when I felt as if I had been given a new engine, $I$ joined an active air force station and the opportunity for fast flying presented itself.

I soon got the impression that fighter pilots were only too pleased to fly eager medical officers but one important necessity was a medical certificate. Medical authority was united and was definitely not happy about my flying. Take the odd helicopter ride if you must, but "Oh, no, fast jets are different." That difference, I discovered, was called $\mathrm{G}$ force.

At the Royal Air Force Institute of Aviation Medicine at Farnborough there is a large centrifuge and although I was able to arrange a visit to the unit I still found a reluctance to help, made all the easier by the fact that, during my short stay, the centrifuge was in the middle of a test programme. My visit served only to reinforce my desire. Sitting in a mock up of a Phantom seat not only whetted my appetite at the time, but a little familiarity with surroundings was to come in useful later.

\footnotetext{
Akrotiri, Cyprus

DE BRADFORD, MB, CHB
}

About a year after Farnborough the breakthrough occurred when I discovered that fitness to fly fell into three categories. Category one referred to the very fit, category two was for the fit, while category three was ordinary passenger flight. I was already category three and if I stopped pushing for category one who knows what might happen?

The morning of the flight was marred by fog but the delay only added to the excitement. I met my pilot, who immediately left me for the next hour with the ground crew. The actual donning of flying kit for the first time was a lot more exacting than watching a well trained instructor slip in and out of his garments in front of a class. The anti-G suit fits over the lower abdomen and legs and many minutes were spent adjusting and readjusting until the fit was perfect. Next came the Mae West, a sort of short string vest on which or in which were found the few essentials of life, such as the inflatable life jacket, the personal radio beacon, the oxygen regulator, and the lanyard for fixing me to my life raft. Last came the long and detailed fitting of the helmet with its own trimmings, the face mask, and visors.

Just over an hour later my pilot reappeared and we went over the emergency drill. The usual chestnut for first time flyers is for the pilot to say "and if I shout 'Eject' don't attempt to discuss it because I will no longer be there." I got what is probably standard chat for doctors. "The ejection grip is between your legs, a not unusual place to grab in an emergency. Takes a good pull, sometimes up to midchest, but there's usually no difficulty when the adrenalin is running." I was reassured that in the event of an ejection I could expect the rescue helicopter to be on site almost before I landed (it had occurred to me that if I did eject I would also be getting my first ever parachute jump).

As the flying suit was tailored to the individual so the seat of a fast jet is tailored to the trappings on the suit-oxygen tube, G-suit, and radio. Only when man and his seat were one and the same was the seat made active. The days of climbing out and jumping, holding 